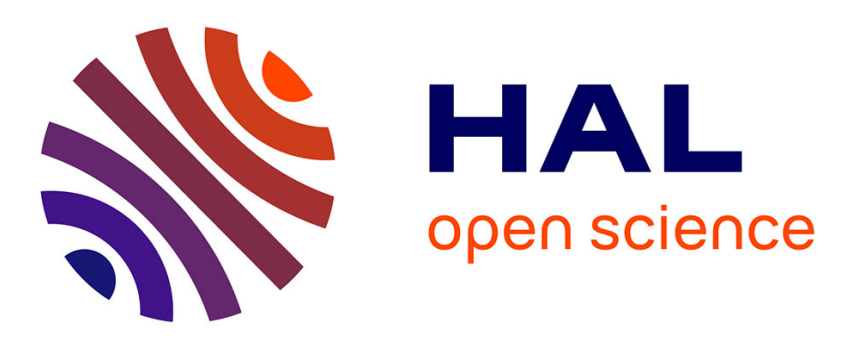

\title{
Size-dependent Analysis and Experiments of Bulk PMN-PT [001] Piezoelectric Actuator for MOEMS Micro-Mirrors.
}

Dragos Adrian Ciubotariu, Ioan Alexandru Ivan, Cédric Clevy, Philippe Lutz

\section{- To cite this version:}

Dragos Adrian Ciubotariu, Ioan Alexandru Ivan, Cédric Clevy, Philippe Lutz. Size-dependent Analysis and Experiments of Bulk PMN-PT [001] Piezoelectric Actuator for MOEMS Micro-Mirrors.. IEEE/ASME International Conference on Advanced Intelligent Mechatronics, AIM'14., Jul 2014, Besançon, France. pp.1267-1272. hal-01324690

\section{HAL Id: hal-01324690 \\ https://hal.science/hal-01324690}

Submitted on 1 Jun 2016

HAL is a multi-disciplinary open access archive for the deposit and dissemination of scientific research documents, whether they are published or not. The documents may come from teaching and research institutions in France or abroad, or from public or private research centers.
L'archive ouverte pluridisciplinaire HAL, est destinée au dépôt et à la diffusion de documents scientifiques de niveau recherche, publiés ou non, émanant des établissements d'enseignement et de recherche français ou étrangers, des laboratoires publics ou privés. 


\title{
Size-dependent Analysis and Experiments of Bulk PMN-PT [001] Piezoelectric Actuator for MOEMS Micro-Mirrors
}

\author{
Dragos Adrian Ciubotariu, Ioan Alexandru Ivan, Cédric Clévy, Philippe Lutz
}

\begin{abstract}
This paper presents the modeling, fabrication, FEM simulation and validation of a PMN-PT [001], bulk micro-actuator intended for integration in smart Micro-OptoElectrical-Mechanicals Systems (MOEMS). Unlike the majority of piezoelectric materials, PMN-PT [001] has the ability to generate large-stroke out-of-plane actuation; this is due to its high longitudinal piezoelectric coefficient of up to $4500 \mathrm{pm} / \mathrm{V}$. After an introduction on MOEMS actuation, a concise modeling is given. The FEM simulations are then presented, highlighting actuation-induced shape specificities. The focus is placed on planar displacement and on possible shape generation. Actuation reached values as high as $680 \mathrm{~nm}$ for a $200 \mu \mathrm{m}$ thick layer. Spherical shape generation was also studied. After presenting the fabrication of a basic piezo-patch mirror, the experimental verification is provided, outlining the influence of the contact interface size and nature.
\end{abstract}

\section{INTRODUCTION}

This paper sets to address smart material integration in microsystems, especially since the functional needs that these systems need to meet are more and more demanding in terms of scale and accuracy. Applications such as Micro-ElectroMechanical Systems (MEMS) [1], biomedical [2], [3], microrobotics or micromanipulation [4] require the use of easy to integrate, precise smart materials, capable of a high dynamic response range. A field of great interest is also Micro-Opto-Electro-Mechanical Systems (MOEMS), where highly accurate actuation is needed. Such adaptive optics applications are found in interferometry [5], spectrometry [6], [7], scanners [8] and image aberration corrections [9].

Of high interest in the integrability of such actuators in MOEMS is the capability to precisely alter an optical signal. The actuation range needed is around $1 \mu \mathrm{m}$, around the wavelength of visible light.

There is a wide range of smart materials in use today, such as polymers [10], [11], ferromagnetic [12] or thermoelectric [13]. The best results, however, are found

D.A. Ciubotariu, Cedric Clevy and Philippe Lutz are with the FEMTOST Institute (UMR CNRS 6174) - UFC/ENSMM/UTBM, AS2M Department, 24 Rue Alain Savary, 25000 Besancon, France (phone: +33381-402-803; fax: +333-381-853-998; e-mail: \{adrian.ciubotariu, cclevy, plutz\}@ femto-st.fr).

I.A.Ivan is with Université de Lyon, CNRS UMR5513, Ecole Nationale d'Ingénieurs de Saint-Etienne (ENISE), Laboratoire de Tribologie et Dynamique des Systèmes (LTDS), Université de Lyon, ENISE, LTDS, UMR 5513 CNRS, 58 Rue Jean Parot, 42023 Saint-Etienne Cedex 2, FRANCE email: ivan@enise.fr.

D.A. Ciubotariu and I.A. Ivan are also with Valahia University of Targoviste, FIE/ICSTM, B-dul Unirii 18-20, 130082 Targoviste, Romania; e-mail: ivan@valahia.ro. when piezoelectric materials [14] are being used, due to their integrability, resolution and dynamics. Such applications are for the optics used in astronomy, where adaptive lenses and mirrors improve imaging [15]. Although PZT (Lead Zirconium Titanate) is widely used in multi DoF (Degrees of Freedom) applications, where large bandwidth and forces [16], [17] are needed, other materials are being developed in order to gain in performance. One such new material is PMN-PT (Lead Magnesium Niobate-Lead Titanate) and it's of particular interest due to its very high piezoelectric coefficients (up to 6 times than those of PZT). Recent improvements in fabrication techniques have shown the possibility of obtaining $d_{33}$ values of up to $4500 \mathrm{pm} / \mathrm{V}$ [18], making PMN-PT useful in transducers [19] and other types of sensors (mechanical properties aren't well known due to the wide variety of sub-groups in the PMN-PT family and the fact that it is relatively new - available since 2000). Because of these facts, the interest in using PMN-PT within MOEMS and the limited knowledge concerning modeling and behavior of PMN-PT this paper will focus on the analysis of a specific type of PMN-PT regular uniaxial cut [001]. This presents as a very good candidate for MOEMS micromirror actuation. This is due to its very large longitudinal deformation, unlike PZT ceramics which are regularly used in cantilever structures using transverse deformation.

PMN-PT is an anisotropic material which has shown very good performances when used in bulk, in comparison with standard multilayered PZT. In order to investigate if this type of material is suitable when used as a micromirror actuator in the proposed MOEMS, a series of FEM simulations have been done for a primary evaluation of its performances.

The paper sets to focus on the utilization of PMN-PT as bulk material to actuate a micromirror in a MOEMS, while investigating material behavior and actuation due to shape specificities. The relation between the shape of the actuator and the solder surface is also analyzed. This is done in order to better assess the relation between the needed (depending on application) and the obtainable actuation.

The paper is structured as follows: Section II will present the basic modeling of the piezoelectric actuator, Section III will present the size-dependent FEM analysis towards flat or spherical actuated shape, Section IV will present some experimental results. A conclusion that highlights the most important aspects will end the paper.

\section{MODELING}

\section{A. Concept RFS-MoB}

The actuator is intended to be part of a Reconfigurable Micro-Optical Bench (RFS-MoB - as in Figure 1) and as 
such, it will have to comply not only with surface limitations, but also have minimal overall influence on the system.

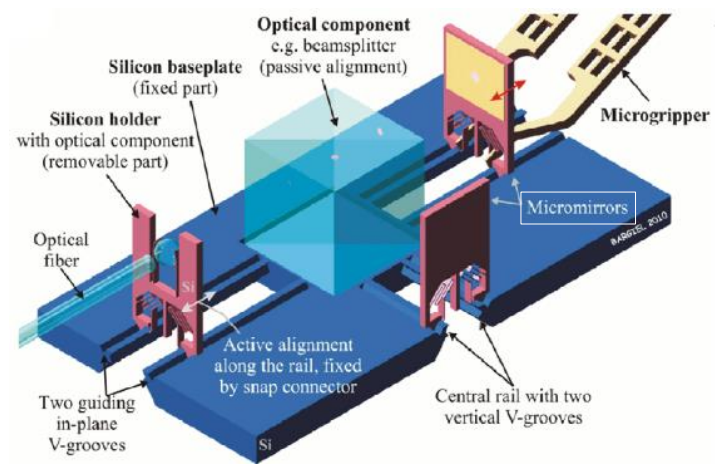

Figure 1. Types of structures used in a RFS-MOB [20].

As part of a RFS-MoB in the development stage [20], the piezoactuator will have to fall under specific requirements, one of which is the maximum work surface. Figure 2 shows part of the RFS-MoB with vertical holders sized at $1,2 \times 0,8 \times 0,05 \mathrm{~mm}^{3}$. The piezo actuator needs to have an outof-plane movement ( $\mathrm{Z}$ axis) and will be positioned on a support similar to Holder 1 (Figure 2). The actuation range also has to exceed $\lambda / 2$, enabling the system to generate interferometer sweeps, where $\lambda$ is the wavelength of the light used in measurements. Another requirement that needs to be met is the actual thickness of the piezoactuator as to not topple the holder.

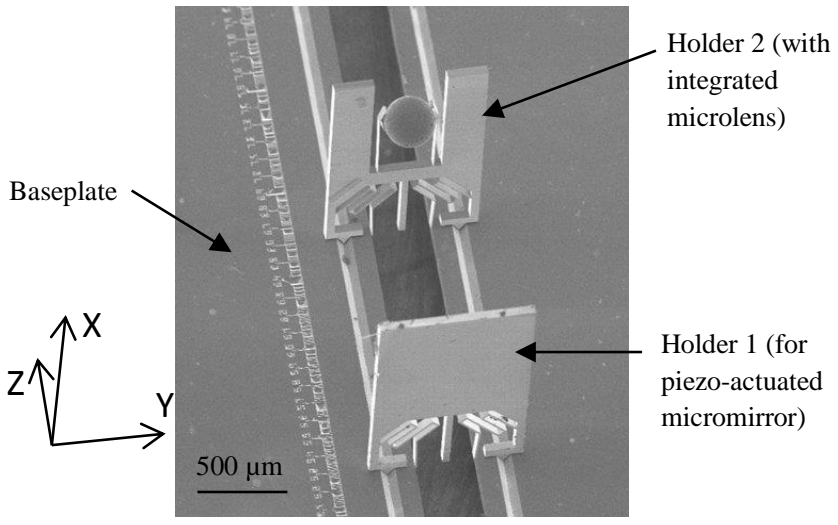

Figure 2. The RFS-MoB in the preliminary stages [20].

\section{B. Piezoelectric coefficients}

In the chosen case, actuation along the $\mathrm{Z}$-axis, the piezoelectric material will be used longitudinally, the displacement of interest being the one influenced by the $d_{33}$ piezoelectric coefficient. The actuation along the $\mathrm{X}$ and $\mathrm{Y}$ axes is not of direct interest in the desired movement.

$$
\begin{gathered}
\mathrm{S}_{1}=\frac{\Delta h}{h}=\mathrm{d}_{33} \mathrm{E}_{3}=\mathrm{d}_{33} \frac{\mathrm{V}}{h} \\
\mathrm{~d}_{33}=\frac{\Delta h}{\mathrm{~V}}
\end{gathered}
$$

Where $S_{1}$ is the specific deformation, $E_{3}$ is the $\mathrm{Z}$ component of the electric field, $h$ is the thickness of the actuator, $\Delta h$ is the displacement and $V$ is the applied voltage.
Like mentioned before, there is a workspace limitation $\left(800 \times 800 \mu \mathrm{m}^{2}\right)$ and, therefore, the piezoelectric actuator is of parallelepiped shape, generically called a piezo-patch.

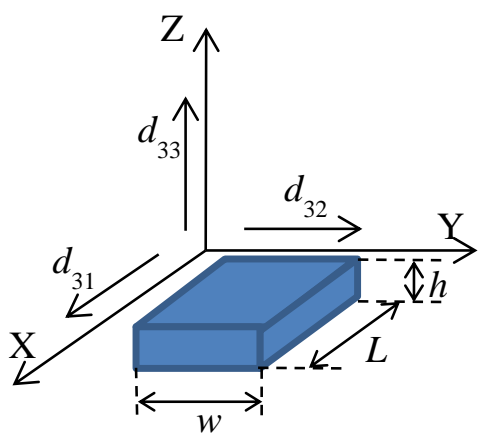

Figure 3. Piezoelectric coefficients of the PMN-PT material in relation to the crystaline orientation and the [001] cut.

This piezoelectric material has the following structure: $(1-\mathrm{x})[\mathrm{Pb}(\mathrm{Mg} 1 / 3 \mathrm{Nb} 2 / 3) \mathrm{O} 3]-\mathrm{x}[\mathrm{PbTiO} 3], \quad$ where the determining factor of the actuation properties is " $x$ ". In our case, the material acquired from TRS Technologies has a composition generically referred to as PMN-33PT, as $20 \times 20 \times 0,2 \mathrm{~mm}^{3}$ plates, cut along [001] direction. Optimal work temperatures are situated between $10^{\circ} \mathrm{C}$ and $50^{\circ} \mathrm{C}$.

In order to simulate the material's behavior under normal conditions, part of the piezoelectric coefficients were determined experimentally, while others were taken from literature. Thus, by the use of image analysis, for PMN-PT [001] plates the following values were found: $d_{31}=-924.47$ $\mathrm{pm} / \mathrm{V}\left(10^{-12} \mathrm{C} / \mathrm{N}\right)$ and $d_{32}=-1035.83 \mathrm{pm} / \mathrm{V}\left(10^{-12} \mathrm{C} / \mathrm{N}\right)$. The third coefficient $d_{33}=2520 \mathrm{pm} / \mathrm{V}(10-12 \mathrm{C} / \mathrm{N})$ was found using a different method, with the aid of an interferometer, described in Section III. These values correspond with the ones found in literature [21], [22].

The values presented in Table I are the ones used in the FEM simulations (which will be detailed in the following section).

\begin{tabular}{|c|c|c|c|}
\hline Constant & Unit & Value[22] & Used \\
\hline$s_{11}^{E}$ & \multirow{6}{*}{$x 10^{-12} \mathrm{~m}^{2} / \mathrm{N}$} & 69.0 & 69.0 \\
\hline$s_{12}^{E}$ & & -11.1 & -11.1 \\
\hline$s_{13}^{E}$ & & -55.7 & -55.7 \\
\hline$s_{33}^{E}$ & & 119.6 & 119.6 \\
\hline$s_{44}^{E}$ & & 14.6 & 14.6 \\
\hline$s_{66}^{E}$ & & 15.2 & 15.2 \\
\hline$d_{15}$ & \multirow{3}{*}{$x 10^{-12} \mathrm{C} / \mathrm{N}$} & 146 & 146 \\
\hline$d_{31}$ & & -1330 & -980 \\
\hline$d_{33}$ & & 2820 & 2520 \\
\hline$\varepsilon_{11}^{T} / \varepsilon_{0}$ & \multirow{2}{*}{ • } & 1600 & 1600 \\
\hline$\varepsilon_{33}^{T} / \varepsilon_{0}$ & & 8200 & 8200 \\
\hline
\end{tabular}

TABLE I. VALUES OF PMN-PT [001] SPECIFIC COEFFICIENTS 


\section{FINITE ELEMENTS SIMULATIONS}

Two scenarios were considered in order to study how the piezo-patch size influences the actuation range and its overall actuated shape.

Firstly a "fixed-free" scenario is studied, like in Figure $4 \mathrm{a}$, where one side is completely fixed, as if it were soldered, and the other one is free to move, resulting in surface deformations. Secondly a "free-free" scenario is studied, like in Figure 4b, where, for modeling reasons, one of the sides has only vertical restrictions (to have a reference plane), while it is free to have planar displacement, and the other one is free to move.
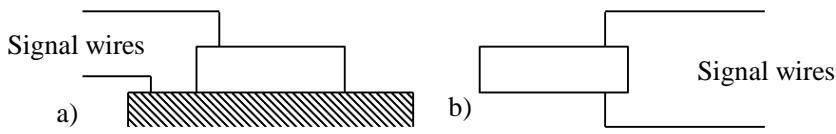

Figure 4. Schematic representations of the considered scenarios a)fixed-free scenario b) free-free scenario.

\section{A. "Fixed-free" scenario}

Here, one side of the piezo-patch is locked in place and the other is free to move. In order to quantify the deformation, differently sized actuators were simulated of the elementary shape presented in Figure 5.

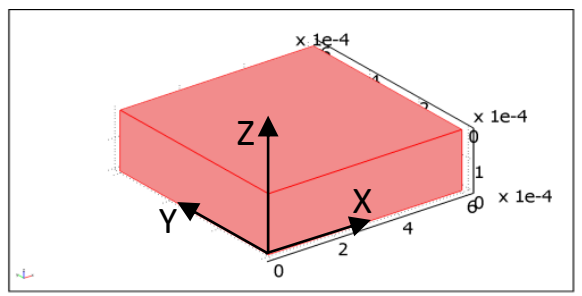

Figure 5 - Elementary shape of the piezo-patch.

As to maintain a consistency in the obtained values, and because the FEM modeling has a linear behavior, all simulations have been done with a $-1 \mathrm{~V}$ potential difference $\left(\mathrm{E}=5 \cdot 10^{-3} \mathrm{~V} / \mathrm{m}\right)$ on piezo-patches $200 \mu \mathrm{m}$ thick.

The following pairs of figures represent 3 important distinct stages in the behavior tendency of the free surface. a)

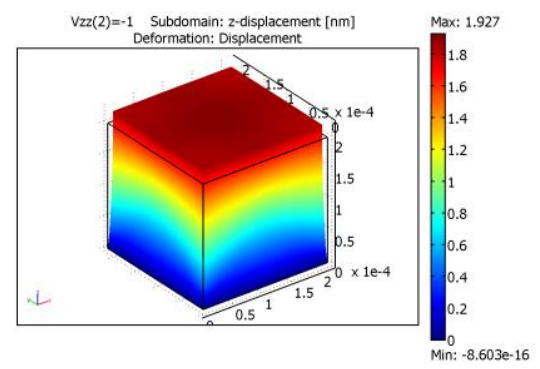

b)

\section{(1)}

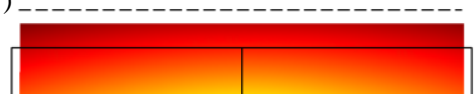

Figure 6 - a) $3 \mathrm{D}$ view of a $225.2 \times 225.2 \mu \mathrm{m}^{2}$ fixed-free piezo-patch; b) Diagonal section view through the top of a piezo-patch shows a flat actuation (1). a)

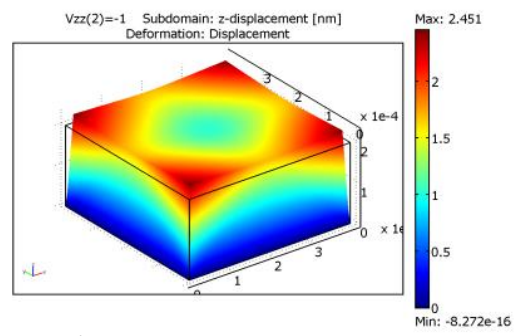

b)

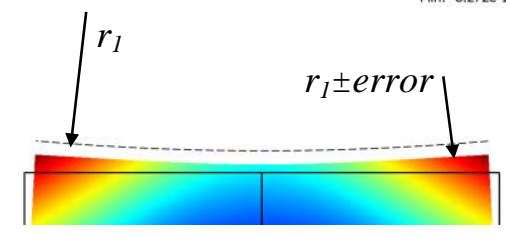

Figure 7. a) $3 \mathrm{D}$ view of a $400 \times 400 \mu \mathrm{m}^{2}$ fixed-free piezo-patch; b) Diagonal cross section view through the top of a piezo-patch showing spherical actuation ( $r_{1}$ is the fitted sphere radius, shifted vertically).

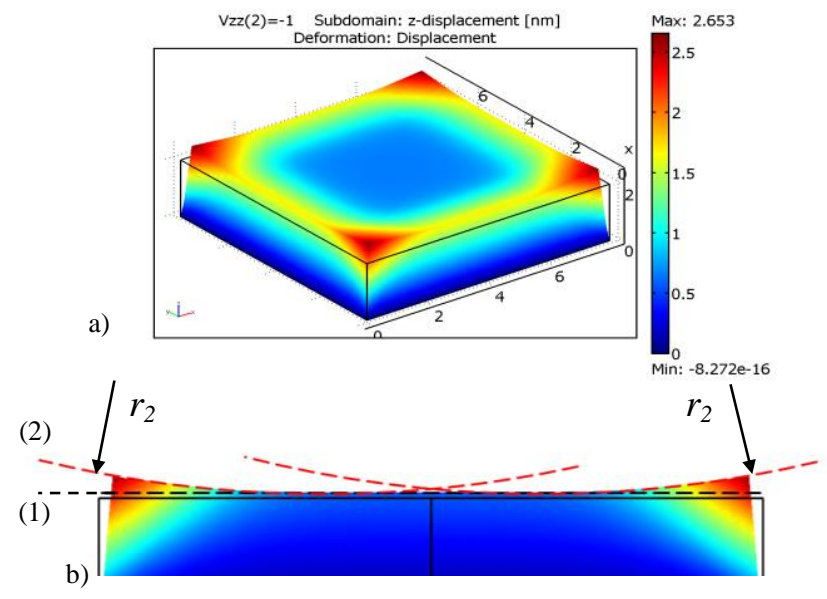

Figure 8. a) 3D view of a $800 \times 800 \mu \mathrm{m}^{2}$ fixed-free piezo-patch;

b) Diagonal section view through the piezo-patch (1) - line following the flat central area

(2) - arcs describing the outer corner curvature ( $r_{2}$ is the radius of spheres that would fit the corners).

Figure 6a presents the situation where, considering the square shape, the free face has a close-to-planar displacement, with a section view in Figure 6b; Figure 7 shows a size of the actuator where the free surface presents a curvature, as it can be observed in Figure $7 b$, where the dotted line follows a perfect circle and Figure 8a presents a situation where, due to the size, the free surface presents different behaviors depending on where the measurement is made: planar displacement in a central region and spherically-curved outer corners.

The measured displacement of the free surface must also follow other very important criteria: a) if a planar displacement is needed, then the maximum aberration must be no larger than $\lambda / 10$ (in our case, the actuation difference between the center region and the outer corners); b) if a spherical deformation is needed, then the free surface deformation must be within 5\% deviation from a sphere.

Figure 9 shows the variation of the PMN-PT [001] bulk piezo-patch surface in comparison to both a flat surface and a 
sphere. The correlation with a fitted flat surface and a fitted sphere is given by means of standard error.

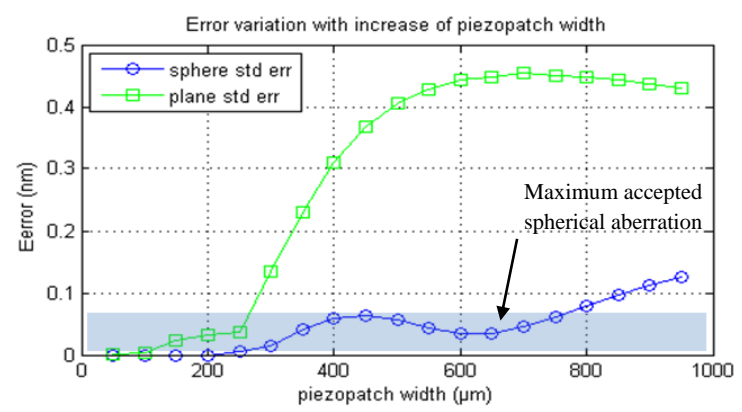

Figure 9. Plane and sphere fit standard error increase with the variation of the piezo-patch width. Simulated applied voltage 1V.

The strip at the bottom reprezents the allowed shperical standard error.

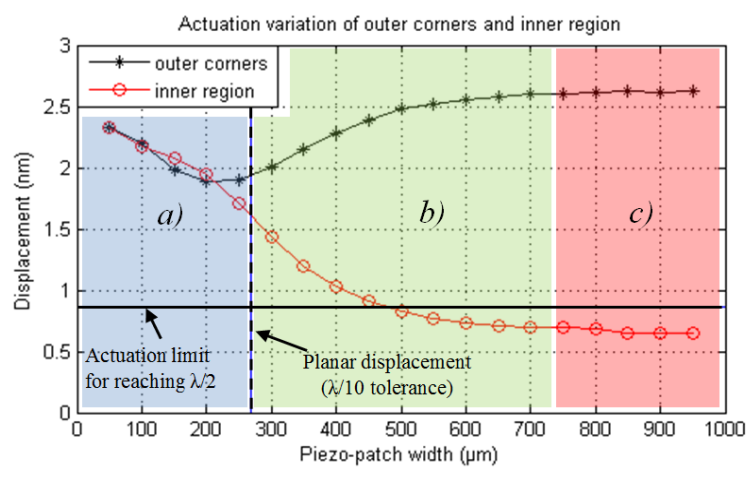

Figure 10. Actuation variation of the piezo-patch measured in the inner region and the outer corners: $a$ ) planar displacement of the whole surface; $b$ ) displacement tangent to a sphere; $c$ ) small planar displacement of inner region with raised corners.

In Figure 10, the actuation in the " $a$ " region is considered planar as it is situated within the margin of aberration. A mirror-like surface is considered planar if the maximum aberration is at most $\lambda / 10$ of the reflected light (in our case red light) achieved at the maximum applied voltage $(400 \mathrm{~V}$ in our case) resulting value $0.1625 \mathrm{~nm} / \mathrm{V}$. This means the piezopatch maximum width is of $265.43 \mu \mathrm{m}$. The piezo-patch regains planarity at a width $>730 \mu \mathrm{m}$. The " $b$ " region is the where the actuation of the piezo-patch shows a spherical aspect. In this region, according to the standard error (Figure 9), the best distribution of points compared to a sphere is observed at a width between $600 \mu \mathrm{m}$ and $650 \mu \mathrm{m}$. Even if the actuation in the "c" area of the graph presented in Figure 9 corresponds to a deformation similar to what can be seen in Figure $8 \mathrm{a}$, it presents little interest due to the very small actuation. This means it has very little usability in real applications as, in order to gain a sufficient displacement $(\lambda / 2$ for example), the applied voltage would exceed the saturation limit of the material.

\section{B. "Free-free" scenario}

Here, one side only has Z-displacement constraints, leaving it to move freely in the X-Y plane (Figure 10). Due to the uniform and constant value of $d_{33}$ throughout the crystalline structure of the PMN-PT, as it is simulated, the noted displacements will be identical, no matter the size (as seen in Figure 10) and proportional with $d_{33}, 2,52 \mathrm{~nm} / \mathrm{V}$.

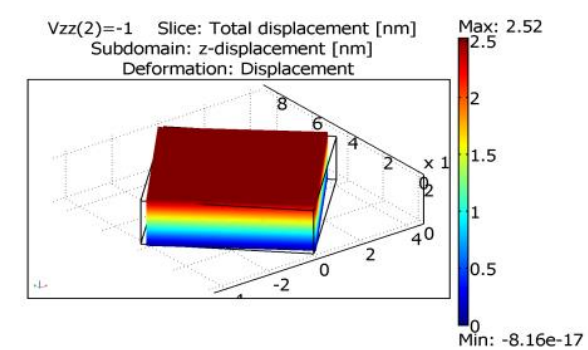

Figure 11. FEM simulations for a $600 \times 600 \mu \mathrm{m}^{2}$, "free-free" scenario, uniform vertical displacement: $2.52 \mathrm{~nm} / \mathrm{V}$.

\section{EXPERIMENTAL VALIDATION}

PMN-PT has the special characteristic that it can be polled at room temperature. It also has a low coercive field and thus, can only be used in unipolar fashions. The test sample was cut from a $200 \mu \mathrm{m}$ thick plate, manufactured by TRS Technologies, and was chosen to be $600 \times 600 \mu \mathrm{m}^{2}$. This also makes the piezo-patch easy to manipulate and fabricate.

To determine the poling directions for the batch from which the test samples were fabricated, an exposure to a potential difference of $400 \mathrm{~V}$ (from $-200 \mathrm{~V}$ to $200 \mathrm{~V}$ ) with a $0.0005 \mathrm{~Hz}$ sweep frequency was performed. Figure 12 presents the results.

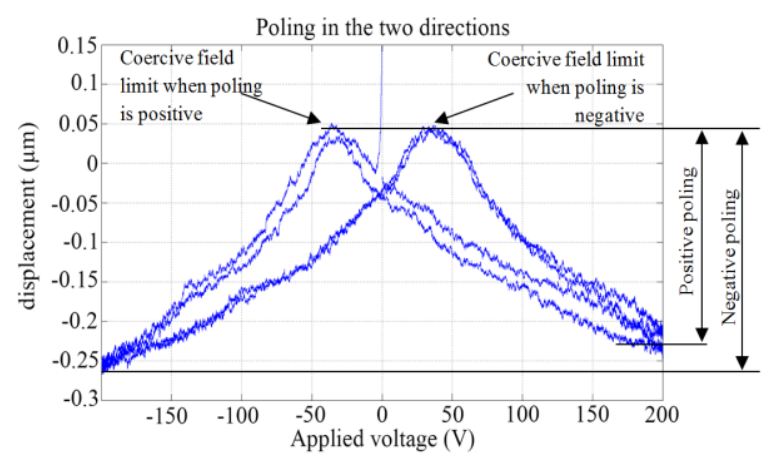

Figure 12. Experimental displacement of a piezo-patch for applied voltage between $-200 \mathrm{~V}$ and $200 \mathrm{~V}$. Larger displacement is obtained with negative polling.

It can also be observed that the coercive field is situated around $\pm 40 \mathrm{~V}$, depending on the polling direction.

The following test sample was conceived in order test the accuracy of the FEM simulations and to measure the vertical displacement (Figure 13, while Figure 14 presents the structure), for the first presented scenario, the "fixed-free" case. The solder used was EPO-TEK® H37, a conductive, silver-based adhesive with 20-30 $\mu \mathrm{m}$ size grains.

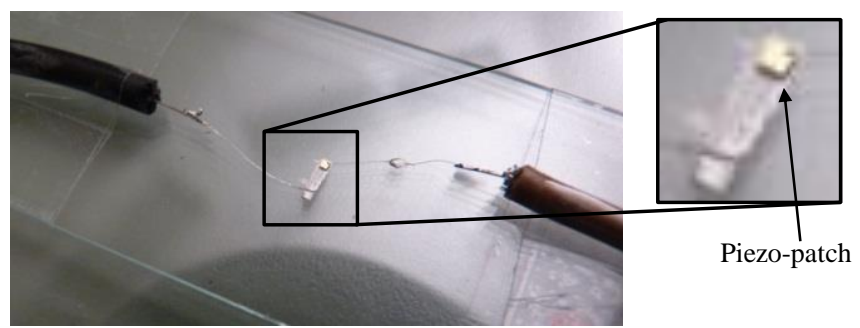

Figure 13. Experimental sample, with a closeup view of the piezo-patch on the right. 


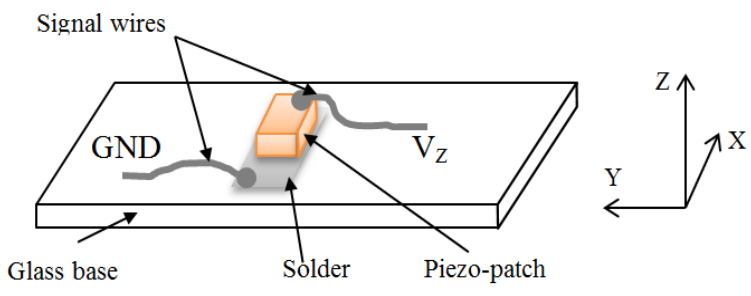

Figure 14. Soldered PMN-PT [001] actuator.

The actuation range was measured experimentally and was found to be larger than expected from the FEM simulations results, as seen in Figure 15a. This is due to the fact that, in reality, the solder does offer a degree of in-plane freedom between the base and the fixed side due to its nonnegligible $(\sim 20 \mu \mathrm{m})$ thickness and mechanical composition. It can be noted that there is nonlinearity in the $d_{33}$ coefficient, as shown in Figure 15b.
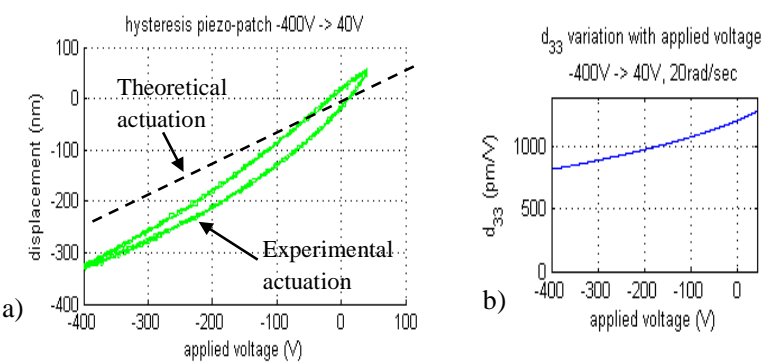

Figure 15. Experimental results with fixed-free piezo-patch. a) Behavior under a sinusoidal signal b) apparent $d_{33}$ variation due to solder.

In order for the piezo-patch to be considered useful it needs to generate actuation larger than $\lambda / 2$. The actuation measured is $\sim 380 \mathrm{~nm}$ for the $440 \mathrm{~V}$ potential difference, making it a viable candidate for phase-shifted visible light interferometry.

Another sample was fabricated to measure the actuation range in near-perfect free-free conditions. The sample is presented in Figure 16, while Figure 17 represents the structure.

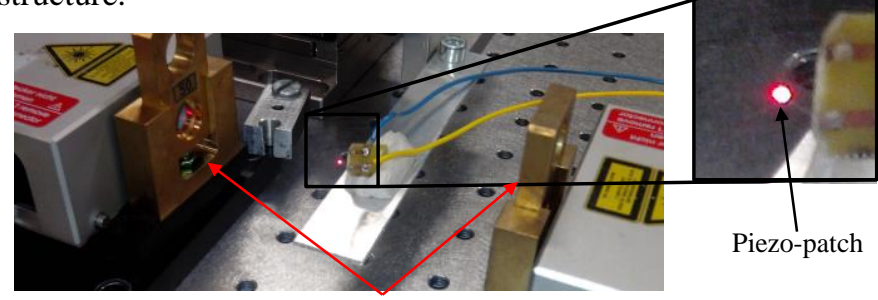

Interferometer heads

Figure 16. Experimental setup for the free-free scenario, with a closeup of the piezo-patch on the right. The bright red spot is situated on the piezopatch both sides.

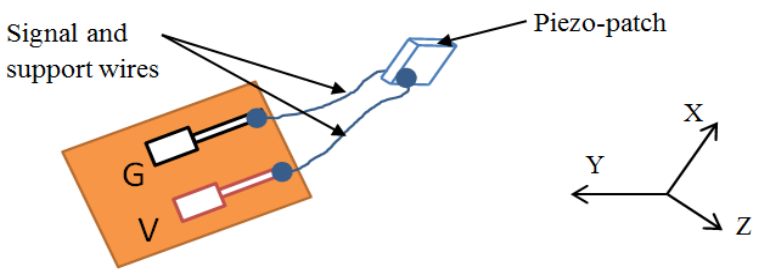

Figure 17. Test piezo-patch to test the „free-free” scenario.

The two support wires are soldered in a corner of the patch as to ensure a large enough surface for the measurements and to not induce rotation. Measurements were done using two interferometer heads through a differentiation method. Figure 18a presents the displacement curve, while Figure $18 \mathrm{~b}$ presents the apparent $d_{33}$ variation. For low voltages, $d_{33}$ value is close to theoretical the one. For values exceeding $100 \mathrm{~V}$ saturation in the material becomes significant therefore the experimental actuation is found to be $40 \%$ lower than the theoretical one.

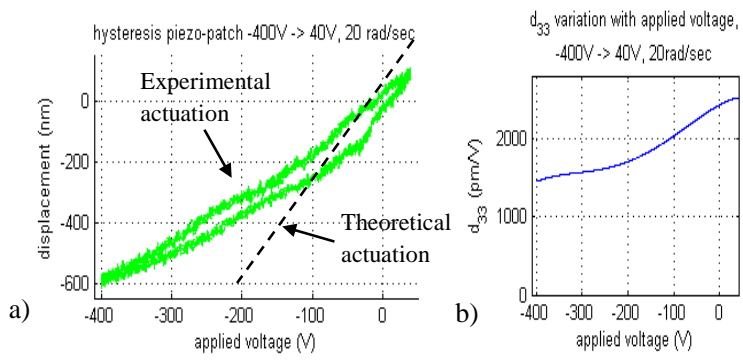

Figure 18. Experimental results with freee-free piezo-patch a) Behavior under a sinusoidal signal; b) apparent $d_{33}$ variation.

However, with respect to the fixed-free case (Figure 15a) an increase in actuation is clearly noticed, up to $680 \mathrm{~nm}$. Though this increase in actuation is a significant gain $(\sim 80 \%)$, another noticed aspect is the loss of dynamic capabilities, as it can be observed in Figure 19. The step signal were lowered to $200 \mathrm{~V}$ in order not damage the piezopatch connections.
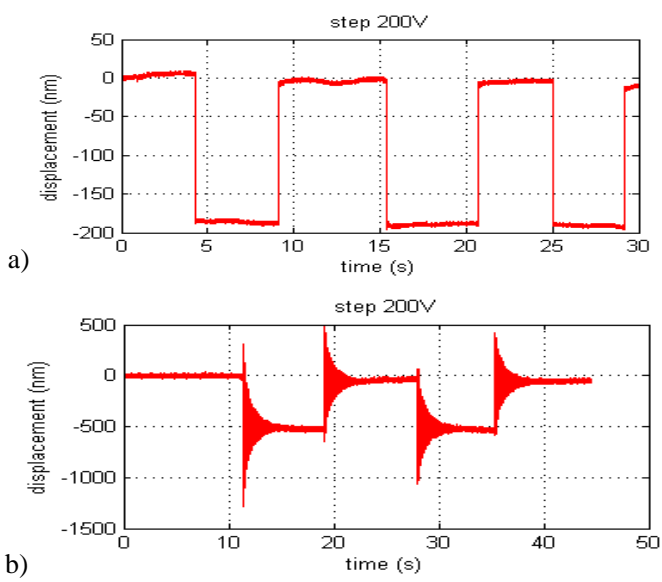

Figure 19. Dynamic experimental results.

a) step response for the soldered (fixed-free) piezo-patch b)step response for the wire-suspended (free-free) piezo-patch.

While the soldered (fixed-free) piezo-patch has a very short transient time, even faster than the high voltage amplifier slew rate, in the case of free-free piezo-patch large 
low frequency oscillations $(\sim 90 \mathrm{~Hz})$ occur. These damped vibrations are due to the propagated shocks form the piezopatch into the long elastic connectors. A tradeoff must be sought for when looking for dynamic actuation.

\section{CONCLUSION}

The paper has presented the essential modeling of a bulk piezo-patch that can be used as an actuator for a MOEMS micromirror made $200 \mu \mathrm{m}$ thick, anisotropic PMN-PT, poled in [001] crystalline direction, and captured the behavior of such an actuator through FEM simulations and verified the actuation range through experimental measurements. One contribution of the paper is observing the shape a soldered piezo-actuator takes with the increase in size (for a basic square shape). It was observed that, in the case of fixed-free piezo-patch, the actuated shape is specific: if a planar displacement is researched ( $\max \lambda / 10$ aberration) then the maximum patch width is $265.43 \mu \mathrm{m}$; if a curved surface is needed (down to a couple dozen $\mathrm{cm}$ in radius) the actuator width should be between $265.43 \mu \mathrm{m}$ and $\sim 730 \mu \mathrm{m}$ and after $\sim 730 \mu \mathrm{m}$ the actuator center regains planarity, but only into the inner region where the actuation range drops significantly. A gain from $380 \mathrm{~nm}$ to $680 \mathrm{~nm}(\sim 80 \%)$ with a decrease in dynamics of several degrees in magnitude is also noted between the "fixed-free" and the "free-free" scenarios. However a significant decrease in dynamics is observed as a result of the piezo-patch fixtures.

The main advantage of using PMN-PT [001] as an integrated actuator is the possibility of it being used in bulk (compared to the multilayered PZT), alongside the simplicity of fabrication with standard techniques, to get the same actuation for lower voltages.

As perspectives, a deeper understanding of the solder layer influence on the actuation range and shape must be further observed, while taking into account the dynamics. Possible applications are twofold: either seeking a planar displacement (usable in phase-shifted micro-interferometers) or a curved, focalizing mirror shape.

\section{ACKNOWLEDGMENT}

These works were partly supported under the National Projects UEFISCDI PN-II-RU-TE-2011-3-0299 (ADMAN), the ANR-11-EMMA-006 (MYMESYS) and the FrancheComte REGION. We acknowledge the Labex ACTION project (contract "ANR-11-LABX-01-01") and the French RENATECH network through its FEMTO-ST technological facility and the technical support of Chritophe Gorecki, Sylwester Bargiel, Nicolas Passily and Marius Ionita.

\section{REFERENCES}

[1] A.Aloga, P.Scanlan, W.Shu, R.L.Reuben "A Scalable SyringeActuated Microgripper for Biological Manipulation", Procedia Engineering vol.47 (2012) pp888-885

[2] Z.W.Zhong, C.K.Yeong "Development of a gripper using SMA wire", Sensors and Actuators A126 (2006) pp375-381

[3] B.A.Wester, S.Rajaraman, J.D.Ross, M.C.LaPlaca, M.G.Allen "Development and characterization of a packaged mechanically actuated microtweezer system", Sensors and Actuators A167 (2011) pp502-511
[4] B.S.Kim, J.S.Park, B.H.Kang, C.Moon "Fabrication and property analysis of a MEMS micro-gripper for robotic micro-manipulation" Robotics and Computer-Integrated Manufacturing, vol.28 (2012) pp50-56

[5] M. Blomberg, H.Kattelus, A.Miranto "Electrically tunable surface micromachined Fabry-Perot interferometer for visible light", Sensors and Actuators A: Physical, vol.162 (2010) pp184-188

[6] Z.Zhihai, M.Xiangxia, G.Yuanjun, W.Wei "A Novel MOEMS NIR Spectrometer" Physics Procedia (ICOPEN), vol.19 (2011) pp110-114

[7] M.Xiang-xia, W.Zhi-yu, Z.Zhi-hai, G.Yuanjun "Analysis and Experimental of Encoding Errors for MOEMS Micro Mirror Spectrometer" Physics Procedia (ICOPEN), vol.19 (2011) 285-290

[8] C.Y.Lin, J.C.Chiou "Design and fabrication of MEMS-based thermally actuated image stabilizer for cell phone camera" SolidState Electronics, vol.77 (2012) pp64-71

[9] A.Tortschanoff, M.Lenzhofer, A.Frank, M.Wildenhain, T.Sandner, H.Schenk, W.Scherf, A.Kenda "Positioning encoding and phase control of resonant MOEMS mirrors" Sensors and Actuator A: Physical, vol.162, (2010) pp235-240

[10] Z.D.Wang, K.Yao, B.Deng, K.Q.Ding "Quantitative study of metal magnetic memory signal versus local stress concentration" NDT\&E International, vol.43 (2010) pp513-518

[11] T.Yan, J.Zhang, G.Feng, J.Chen "Early Inspection of Wet Steam Generator Tubes Based on Metal Magnetic Memory Method", Procedia Engineering, vol.15 (2011) pp1140-1144

[12] M.A.Ahmed, S.T.Bishay, S.M.Salem-Gabalah "Structural characterization and magnetic properties of smart $\mathrm{CuCd}$ ferrite/LaSrCo manganite nanocomposites", Journal of Magnetism and Magnetic Materials, vol.334, (2013) pp96-101

[13] A.I.Boukai, Y.Bunimovich, J.Tahir-Kheli, Jen-Kan Yu "Silicon nanowires as efficient thermoelectric materials", Nature letters vol.451 (2008) pp168-171

[14] F.Liu, X.C.Zhong "Transient response of two collinear dielectric cracks in a piezoelectric solid under inplane impacts", Applied Mathematics and Computation, vol.217 (2010) pp3779-3791

[15] J.Ma, Y.Liu, C.Chen, B.Li, J.Chu "Deformable mirrors based on piezoelectric unimorph microactuator array for adaptive optics correction", Optics Communications, vol.284 (2011) pp5062-5066

[16] C.C.Lee, G.Z.Cao, I.Y.Shen "Effects of residual stresses on leadzirconate-titanate (PZT) thin-film membrane microactuators", Sensors and Actuators A: Physical, vol.159 (2010) pp88-95

[17] S.Gebhardt, L.Seffner, F.Schlenkrich, A.Schoneker "PZT thick films for sensor and actuator applications", Journal of the European Ceramic Society, vol.27 (2007) pp4177-4180

[18] N.Yamamoto, Y.Yamashita, Y.Hosono, K.Itsumi "Electrical and physical properties of repoled PMN-PT single-crystal sliver transducer", Sensors and Actuators A: Physical, vol.200 (2013) pp16-20

[19] Y.Zhang, S.Wang, D.Liu, Q.Zhang, W.Wang, B.Ren, X.Zhao, H.Luo "Fabrication of angle beam two-element ultrasonic transducers with PMN-PT single crystal and PMN-PT/epoxy 1-3 composite for NDE applications", Sensors and Actuators A: Physical, vol.168 (2011) pp223-228

[20] J. Agnus, N. Chaillet, C. Clévy, S. Dembélé, M. Gauthier, Y. Haddab, G. Laurent, P. Lutz, N. Piat, K. Rabenorosoa, M. Rakotondrabe, B. Tamadazte „Robotic Microassembly and micromanipulation at FEMTO-ST", Journal of Micro-Bio Robotics 8, 2013

[21] I.A. Ivan, J. Agnus, M. Rakotondrabe, P. Lutz, N. Chaillet, "Microfabricated PMN-PT on Silicon cantilevers with improved static and dynamic piezoelectric actuation: development, characterization and control", International Conference on Advanced Intelligent Mechatronics (2011), pp403-408

[22] Y. M. Kim, S. H. Lee, H. Y. Lee, and Y. R. Roh, "Measurement of all the material properties of PMN-PT single crystals grown by the SolidState-Crystal-Growth (SSCG) method", Ultrasonics Symposium, (2003) pp1987-1990 